\title{
Corticosterone enhances CSD susceptibility via glucocorticoid receptor activation in familial hemiplegic migraine 1 Cacna1a knock-in mice
}

\author{
R Shyti ${ }^{1}$, K Eikermann-Haerter ${ }^{2}$, OC Meijer ${ }^{3}$, SH van Heiningen ${ }^{1}$, L De Groote ${ }^{4}$, MD Ferrari ${ }^{5}$, C Ayata ${ }^{2}$, \\ AMJ van den Maagdenberg ${ }^{6}$, EA Tolner ${ }^{7 *}$
}

From The European Headache and Migraine Trust International Congress

London, UK. 20-23 September 2012

\section{Introduction}

FHM1 mutant mice carrying the R192Q gain-of-function mutation in CaV2.1 (P/Q-type) calcium channels display enhanced glutamatergic transmission and increased propensity for cortical spreading depression (CSD;1,2). Corticosteroids released after stress also enhance glutamatergic transmission but the relationship between stress and migraine is not well understood.

\section{Objectives}

We aimed to investigate the acute effects of corticosterone and the role of GR activation on CSD susceptibility in FHM1 R192Q knock-in mice.

\section{Methods}

Corticosterone $(20 \mathrm{mg} / \mathrm{kg})$ or vehicle was injected subcutaneously 4 hours before CSD frequency recordings were carried out in FHM1 R192Q mice. A subgroup of mice was injected with the glucocorticoid receptor antagonist mifepristone 50 minutes before corticosterone/vehicle injection.

\section{Results}

Corticosterone injection increased CSD frequency in FHM1 mice compared to vehicle-injected controls but not in wild-types. Pretreatment with mifepristone reduced CSD frequency to the level of vehicle-injected controls. Baseline corticosterone plasma levels were similar in WT and FHM1 mice, while 3 hours after corticosterone administration corticosterone plasma levels were strongly elevated to comparable levels in both WT and FHM1 mice.

\section{Conclusion}

These data suggest that combined effects of glucocorticoid receptor activation and the FHM1 R192Q CaV2.1 gain-of-function mutation on excitatory neurotransmission may play a role in proposed effects of stress on migraine attacks.

\section{Author details \\ 'Dept of Human Genetics, Leiden Univ. Medical Center, Leiden, Netherlands. ${ }^{2}$ Neurovascular Research Laboratory, Dept of Neurology, Massachusetts General Hospital, Harvard Medical School, Boston, USA. ${ }^{3}$ Dept of Endocrinology, Leiden Univ. Medical Center, Leiden, Netherlands. ${ }^{4}$ Dept of Neurology, Leiden Univ. Medical Center, Leiden, Netherlands. ${ }^{5}$ Dept of Neurology ", Netherlands. ${ }^{6}$ Dept of Human Genetics, Leiden Univ. Medical Center, Leiden, Netherlands. ${ }^{7}$ Dept Neurology, Leiden Univ. Medical Center, Leiden, Netherlands.}

Published: 21 February 2013

\section{References}

1. van den Maagdenberg AMJM, et al: A Cacna1a knockin migraine mouse model with increased susceptibility to cortical spreading depression. Neuron 2004, 41:701-710.

2. Tottene A, et al: Enhanced excitatory transmission at cortical synapses as the basis for facilitated spreading depression in $\mathrm{Ca}(\mathrm{v}) 2.1$ knockin migraine mice. Neuron 2009, 61:762-773.

doi:10.1186/1129-2377-14-S1-P85

Cite this article as: Shyti et al:: Corticosterone enhances CSD susceptibility via glucocorticoid receptor activation in familial hemiplegic migraine 1 Cacna1a knock-in mice. The Journal of Headache and Pain 2013 14(Suppl 1):P85. 